ISSN: 2162-3104 Print/ ISSN: 2166-3750 Online

Volume 8, Issue 1 (2018), pp. 284-307

(C) Journal of International Students

http://jistudents.org/

doi: 10.5281/zenodo.1134307

\title{
Analysis of Acculturative Stress and Sociocultural Adaptation Among International Students at a Non-Metropolitan University
}

\author{
Hajara Mahmood \\ Embry-Riddle Aeronautical University, United States \\ Monica Galloway Burke \\ Western Kentucky University, United States
}

\begin{abstract}
This quantitative descriptive study analyzed levels of acculturative stress and sociocultural adaptation among international students at a nonmetropolitan university in the United States related to certain demographic characteristics. Surveys were used to measure international students' levels of acculturative stress and sociocultural adaptation, including five subscales of sociocultural adaptation $(N=413)$. Demographic questions included gender, age, and country of origin, length of stay in the United States, degree level, and English language comfort. Results indicated a negative correlation between students' levels of sociocultural adaptation and acculturative stress. Particularly, increased competency among the five sociocultural adaptation subscales (interpersonal communication, academic/work performance, personal interests and community involvement, ecological adaptation, and language proficiency) decreased levels of acculturative stress among the students.
\end{abstract}

Keywords: acculturation, sociocultural adaptation, acculturative stress, international students

International students are drawn to pursuing their higher education in the United States, which includes undergraduate and graduate degrees as well as English-language training, due to high-quality programs, wide range of 
academic offerings, and higher education system (Chow, 2011; Council for the Advancement of Standards in Higher Education, 2012; Obst \& Forster, 2004), in addition to their internationalization initiatives (Hayward, 2000; Healey, 2008; Johnson, 2011; Stromquist, 2007). Factors such as limited access to quality education, research, and employment opportunities, as well as the demand for a U.S. degree in their home countries are a few influences that drive international students to pursue a higher education degree in the United States (Khatiwada, 2010). Universities recognize the long-term benefits in globalizing higher education, as well as recruiting international students to their campuses, as this can lead to an increase in economic growth and innovation (Adnett, 2010; NAFSA: Association of International Educators, 2013; Wildavsky, 2010) and cultural diversity on campuses (Burbules \& Torres, 2000; La Spada, 2010; Peterson, Briggs, Dreasher, Horner, \& Nelson, 1999). Likewise, the value of education is so great for an international student that they are willing to face the challenges in moving to a new country and environment to pursue a degree for better educational and employment opportunities (Kaczmarek, Matlock, Merta, Ames, \& Ross, 1994). The desire to understand the current status of our international students' acculturation experiences at U.S. universities is imperative to determine whether institutions are meeting their needs and, ultimately, ensuring that these students have a positive educational experience to support their academic persistence.

\section{LITERATURE REVIEW}

\section{International Students' Acculturation and Adaptation in the United States}

While international students greatly influence globalization at U.S. colleges and universities and gain benefits in obtaining a U.S. higher education degree, they often encounter challenges when adapting to a new culture, leading to difficulties and stresses during their acculturation process which ultimately influences their student experience. Although international students come from diverse cultural backgrounds and have differences in language, "being an international student" represents a common minority identity in the United States (Schmitt, Spears, \& Branscombe, 2003; Thomas \& Althen, 1989). When international students arrive in the United States, their expectations often are not easily met (Eustace, 2007). At U.S. college campuses, many international students face various challenges in adapting to the academic and social environment, which might include 
difficulty with the English language and communication, issues with developing friendships, and a lack of knowledge of the American culture (Johnson \& Sandhu, 2007), along with changes in food, finances, housing, and social support (Eustace, 2007). In addition, international students often experience higher levels of discrimination and homesickness in comparison to students from the host country (Poyrazli \& Lopez, 2007). These experiences relate to the challenges and stresses involved during the acculturation process and in adapting to a new culture (Eustace, 2007). As international student population growth is evident at U.S. colleges and universities (Institute of International Education, 2013; Witherel \& Pittman, 2012), it is critical to better understand how to ease the adjustment of international students on college campuses (Al-Sharideh \& Goe, 1998). Ultimately, adjusting to a college campus will positively influence students' experience and satisfaction with the academic and social environment (Hsu, 2011).

\section{Acculturation and Sociocultural Adaptation}

Berry (2005) defined acculturation as the process of adapting to a new culture, which includes, "cultural and psychological change that takes place as a result of contact between two or more cultural groups and their individual members (p. 698). Within the field of acculturation, sociocultural adaptation is a behavioral aspect of cultural competency (Wilson, 2012), relating to the long-term behavioral outcomes one learns in order to perform daily tasks in the host culture (Ward \& Kennedy, 1992, 1993a, 1993b, 1996; Ward \& Rana-Deuba, 1999; Ward \& Searle, 1991). Sociocultural adaptation analyzes one's acquisition of culture learning and social skills (Berry \& Sam, 1997; Ward \& Kennedy, 1999) whereas acculturative stress indicates the negative consequences that result from contact between two distinctive cultural groups (Berry, Kim, Minde, \& Mok, 1987). In essence, acculturation results in culture learning, which contributes to individuals developing multicultural competency in a diverse world (Flaskerud, 2007). However, regardless of the acculturation strategy an individual selects when living in a new culture, they can face some level of stress during their transition to a new cultural environment (Dillard \& Chisolm, 1983; Li \& Gasser, 2005; Olivas \& Li, 2006; Poyrazli, Kavanaugh, Baker, \& AlTimimi, 2004).

The term acculturative stress encompasses different aspects related to the numerous challenges faced by individuals while living in a new culture (Furnham, 2004). The stress often stems from differences in social 
customs, norms, and values, as well as standards in education and politics, among other factors, between the host and original cultures (Yeh et al., 2005). A wide range of factors, known as acculturative stressors, influence international students' levels of stress that determines how these individuals adapt to the culture of the United States. Aponte and Johnson (2000) grouped factors that influence stress into three categories that include "macrosocial influences (e.g., legal constraints, discrimination, degree of tolerance for diversity, academic pressure); an individual's background (e.g., world view, cultural distance from U.S. culture); and individual factors (e.g., age, gender, English language proficiency, coping skills, personality)" (p. 3). Particularly, Eustace (2007) found that international students who perceived their home country cultural values as collectivist, rather than individualistic (cultural distance), experienced significant challenges with acculturation. For example, Poyrazli and Grahame's (2007) research pointed out that many of the Asian, Hispanic, and Middle Eastern international students reported issues in social interactions with Americans both on and off campus, as several encountered various forms of discrimination, in contrast to White German students who experienced fewer difficulties with adjustment as they conveyed no problems in socializing with domestic students.

Literature on international students is ample; however, studies are sparse related to the acculturative stress and sociocultural adaptation of international students. In particular, a substantive amount of studies have been conducted about the needs for international students being met (Allameh, 1989; Butcher \& McGrath, 2004; Mamiseishvili, 2012; Roberts \& Dunworth, 2012; Thiuri, 2011); the challenges faced by international students (Gaw, 2000; Lee \& Rice, 2007; Popov et al., 2012); the psychological and social well-being of international students (Hayes \& Lin, 1994; Jung, Hecht, \& Wadsworth, 2007; Mehta, 2011; O’Reilly, Ryan, \& Hickey, 2010; Sakurai, McCall-Wolf, \& Kashima, 2010; Sobré-Denton, 2011); as well as the adjustment of international students while studying abroad (Andrade, 2006; Khatiwada, 2010; Swami, 2009; Ward \& Kennedy, $1993 \mathrm{a}, 1993 \mathrm{~b})$. In terms of acculturation, very few studies have compared sociocultural adaptation and acculturative stress among international students in the United States.

In order to gain a comprehensive perspective of the international student experience, this study attempted to fill the gap in acculturation research related to sociocultural adaptation and acculturative stress among international students at a non-metropolitan university environment in the United States. The desire to understand the current status of our 
international students' acculturation experiences at U.S. universities is imperative to determine whether institutions are meeting their needs and, ultimately, ensuring that these students have a positive educational experience to support their academic persistence.

\section{RESEARCH METHOD}

In this investigation, an analysis of variance (ANOVA) was used, a quantitative research design that is an inquiry "grounded in the assumption that features of the social environment constitute an objective reality that is constant across time and settings" (Gall, Gall, \& Borg, 2007, p. 650), to gain a better perspective on key factors influencing acculturation and adaptation of international students. The use of quantitative methods to study social science research problems allows for a broader study involving a greater number of subjects, enhancing the generalization of the results, greater objectivity and accuracy of results, a summarization of vast sources of information and comparisons across categories and over time, and personal bias to be avoided by researchers by keeping a "distance" from participating subjects and employing subjects unknown to them (Babbie, 2010). The research sought to determine the status of acculturative stress and sociocultural adaptation of the international college student population through participants' self-report to conclude whether acculturative stress and sociocultural adaptation levels are related by utilizing instruments that measure these constructs. The following research questions were proposed:

1. How does the level of acculturative stress relate to the levels of overall sociocultural adaptation and the five subscales of sociocultural adaptation (interpersonal communication, academic/ work performance, personal interests and community involvement, ecological adaptation, and language proficiency) among international students at a non-metropolitan university in the United States?

2. Do significant differences exist between international students' selected demographic variables (gender, age, degree level, and English language comfort) and the dependent variables of levels of acculturative stress, overall sociocultural adaptation, five subscales of sociocultural adaptation, satisfaction with the overall college experience, and satisfaction with the university? 


\section{Participants}

The participants for this study included international students $(N=$ 880) from two campuses of a 4-year public, large institution in the south central United States. All international students were holding an F-1 or J-1 visa, with the exception of Canadian students, and were enrolled as full-time students at either the undergraduate or graduate level or enrolled in an English language learning program which includes the English as a Second Language Institute (ESLI) and Navitas Program (University Pathway Program and pre-master's program designed to prepare international students for university studies). After IRB approval, questionnaires were distributed using two methods-paper and online surveys. Paper surveys were administered to 285 international students and online surveys were completed by 128 international students, with a total of 413 international student participants.

Based on the population of international students, the sample included 438 students in which 413 had sufficient responses to be included in the results, indicating a $47 \%$ response rate. Of the 880 international students enrolled, 525 were pursuing bachelor's degrees, 216 in master's programs, five in doctoral programs, and 134 enrolled in English language training.

For this study, there were more male respondents $(N=271,66 \%)$ than females $(N=142,34 \%)$ with ages ranging from 16 to 44 ; with $67 \%$ of the international students of traditional age, particularly between the ages of 18 to 24 . Regarding the international students' length of stay, the majority in this study reported to have lived in the United States less than 2 years (85\%), 20 months on average. For the majority of students, this was the first time they were enrolled at a higher education institution in the United States, as $86 \%(N=356)$ indicated they did not attend another institution in the United States. prior to enrolling at the university in this study, with 33 reporting they were at another institution only for one to two semesters. Pertaining to language, $91 \%$ identified English as their second language.

\section{Measures and Instrumentation}

The research incorporated a sociocultural adaptation questionnaire, the revised version of the Sociocultural Adaptation Scale (SCAS-R), comprised of five subscales (interpersonal communication, academic/work performance, personal interests and community involvement, ecological adaptation, and language proficiency); an acculturative stress questionnaire, 
The Acculturative Stress Scale for International Students (ASSIS); and a demographics survey to examine whether certain factors influence sociocultural adaptation and acculturative stress levels. The Acculturative Stress Scale for International Students (ASSIS) developed by Sandhu and Asrabadi (1994) was designed to measure the difficulties encountered by international students with personal, social, and environmental changes upon arrival to a new country, often known as the cultural-shock or acculturative stress experience. The demographic survey asked respondents about their gender, age, degree level, country of origin, length of time in United States, length of time at higher education institution, and English language.

\section{The Acculturative Stress Scale for International Students}

The Acculturative Stress Scale for International Students (ASSIS) scale was chosen for this study as it is the only instrument designed to measure acculturative stress for international students. The identified major contributing factors included perceived discrimination (eight items), homesickness (four items), perceived hatred/rejection (five items), fear (four items), guilt (twi items), stress due to change (three items), and non-specific concerns (10 items). The total scores ranged from 36 to 180 , with higher scores representing higher levels of acculturative stress. The 36 -item scale has high internal consistency, as measured by Cronbach's alpha, which ranged from .92 to .94 (Constantine, Okazaki, \& Utsey, 2004; Sandhu \& Asrabadi, 1994; Wei et al., 2007) and indicated an evidence for reliability. Reliability also was established through the Guttman split-test, showing the reliability to be .97 (Sandhu \& Asrabadi, 1994, 1998). Validity also was supported by factor analysis (Sandhu \& Asrabadi, 1994).

\section{Sociocultural Adaptation Scale}

A revised version of the Sociocultural Adaptation Scale (SCAS-R) developed by Wilson (2012) was used, as this instrument examines "sociocultural adaptation as a measure of behavioral adjustment through the use of new terminology concerning an individual's newly-acquired competencies within a novel cultural environment" (p. 144). The SCAS-R consisted of 21 items to which participants are asked to respond to all questions using a 5-point Likert-type scale ranging from $1=$ Not at all Competent to 5 = Extremely Competent. Scores obtained from the scale indicate the respondents' perceptions about living in another culture in order 
to understand the social and cultural difficulties they face. Based on the factor loadings of the 21-item scale, five subscales were identified that included one's competency with interpersonal communication (seven items), academic/work performance (four items), one's personal interests and community involvement (four items), ecological adaptation (four items), and one's language proficiency while living in a different culture (two items). The mean scores range from 1 to 5, with lower scores indicating greater social difficulties and sociocultural adaptation problems; higher scores representing greater competency (skills or behaviors) in a new cultural environment. The overall reliability of the 21 -item scale was found to be excellent, as Wilson (2012) reported the Cronbach's alpha to be .92 .

\section{Data Analysis}

An ANOVA analysis was conducted to determine the relationship between levels of sociocultural adaptation and acculturative stress among the international students. The Statistical Analysis System (SAS) version 9.3 was utilized for data analysis. The data analysis procedure for the first research question involved a correlational statistical analysis to determine whether any relationship existed between the levels of sociocultural adaptation and acculturative stress among international students. The data analysis procedure used to answer the second research question was a comparison of means through one-way ANOVA to explore whether differences were evident among the means for selected demographic factors and students' levels of sociocultural adaptation, acculturative stress, and satisfaction. An alpha level of .05 was used for the statistical analyses.

\section{RESULTS}

A Pearson's correlation analysis was used to examine the relationships between acculturative stress and sociocultural adaption levels among international students. The data revealed that a significant negative relationship exists between international students' overall levels of acculturative stress and sociocultural adaptation $(r=-.23, p<.01)$; however, this indicates a weak relationship. In addition, the correlations between students' overall levels of acculturative stress with the five subscales for sociocultural adaptation were determined indicating all five subscales had a significant negative relationship with overall acculturative stress levels; however, all relationships also were very weak. Among the five subscales, interpersonal communication exhibited the strongest 
correlation, although this relationship also was very weak $(r=-.25, p<$ $.01)$. The remaining four subscales included academic/work performance $(r$ $=-.20, p<.01)$; personal interests and community involvement $(r=-.10, p$ $<.01)$; ecological adaptation $(r=-.12, p<.01)$; and language proficiency $(r$ $=-.16, p<.01)$.

Table 1. Means, standard deviations, and intercorrelations for acculturative stress and sociocultural adaptation levels among international students.

\begin{tabular}{lrrr}
\hline & & & $\begin{array}{c}\text { Pearson } \\
\text { correlation } \\
\text { coefficients }\end{array}$ \\
\cline { 2 - 4 } Variable & $\boldsymbol{N}$ & $\boldsymbol{M}(\boldsymbol{S D})$ & $\begin{array}{c}\text { Acculturative } \\
\text { stress }\end{array}$ \\
\hline Acculturative stress & 413 & $91(23.72)$ & \\
Sociocultural adaptation & 413 & $3.50(0.61)$ & $-.23^{* *}$ \\
Sociocultural adaptation subscales & & & $-.25^{* *}$ \\
$\quad \begin{array}{l}\text { Interpersonal communication } \\
\text { Academic/work performance }\end{array}$ & 413 & $3.43(0.68)$ & $-.20^{* *}$ \\
$\quad \begin{array}{l}\text { Personal interests and community } \\
\quad \text { involvement }\end{array}$ & 413 & $3.61(0.70)$ & $-.10^{* *}$ \\
$\quad \begin{array}{l}\text { Ecological Adaptation } \\
\text { Language Proficiency }\end{array}$ & 413 & $3.51(0.72)$ & $-.12^{* *}$ \\
\hline
\end{tabular}

Note. $* p<.05 ; * * p<.01$.

For the second research question, one-way ANOVA was utilized to examine the differences of each of the demographic factors and the dependent variables. In the examination of the difference by gender for each of the dependent variables, the means $(S D)$ for males $(N=267)$ was 93.01 (22.79) and $87.93(25.13)$ for females $(N=142)$.

A significant difference was found as the male international students had a significantly higher mean for acculturative stress levels $(F=4.29,1$, 407, $p<.04$ ), which indicated they had slightly higher levels of acculturative stress. To address this research question in terms of sociocultural adaptation, an ANOVA was conducted to test the differences between gender and overall sociocultural adaptation levels, along with the five subscales of sociocultural adaptation among the international students. Female international students had a significant, slightly higher means for total sociocultural adaptation levels $(F=7.66,1,411, p<.01)$, along with 
four specific sociocultural adaptation subscales which included interpersonal communication $(F=4.25,1,411, p<.04)$; academic and work performance $(F=9.67,1,411, p<.002)$; ecological adaptation $(F=7.83,1,411, p<$ $.01)$; and language proficiency $(F=7.62,1,411, p<.01)$.

Table 2. Means and standard deviations for sociocultural adaptation and five subscales of sociocultural adaptation by gender.

\begin{tabular}{lcccc}
\hline & \multicolumn{2}{c}{ Male } & \multicolumn{2}{c}{ Female } \\
\cline { 2 - 5 } & $\boldsymbol{N}$ & $\boldsymbol{M}(\boldsymbol{S D})$ & $\boldsymbol{N}$ & $\boldsymbol{M}(\boldsymbol{S D})$ \\
\hline Sociocultural adaptation & 271 & $3.61(0.57)$ & 142 & $3.44(0.67)$ \\
Sociocultural adaptation subscales & & & & \\
$\quad$ Interpersonal communication & 271 & $3.38(0.64)$ & 142 & $3.53(0.76)$ \\
$\quad$ Academic/work performance & 271 & $3.53(0.69)$ & 142 & $3.76(0.73)$ \\
$\quad$ Personal interests and community & 271 & $3.30(0.66)$ & 142 & $3.40(0.78)$ \\
$\quad$ involvement & & & & \\
$\quad$ Ecological adaptation & 271 & $3.44(0.70)$ & 142 & $3.65(0.77)$ \\
$\quad$ Language proficiency & 271 & $3.68(0.91)$ & 142 & $3.93(0.87)$ \\
\hline
\end{tabular}

Note. Rating of each behavior ranged from 1 (not at all competent) to 5 (extremely competent).

The demographic variable of age was analyzed among international students, for which students were classified as traditional (between the ages of 18-22) and non-traditional (those at age 24 or older), to test the differences between age and acculturative stress. Traditional students had a slightly higher mean for levels of acculturative stress; however, a significant difference was not evident. The mean $(S D)$ for traditional students $(N=265)$ was 91.29 (24.08) and 90.98 (22.69) for non-traditional students $(N=130)$.

An ANOVA was conducted to test the differences between age and overall sociocultural adaptation levels, along with the five subscales of sociocultural adaptation among the international students. A significant difference was evident for academic/work performance $(F=5.11,1,397, p$ $<.02)$, as non-traditional students had a significant higher mean value in comparison to traditional students. However, the differences among traditional and non-traditional students were not significant for these variables.

An ANOVA was conducted to test the differences between degree level and acculturative stress among the international students in the study. No significant differences were found in mean values between 
undergraduate $(N=252 ; M=92.56, S D=22.60)$ and graduate students $(N=$ $155 ; M=89.37, S D=25.09$ ) for the variable of acculturative stress; however, undergraduate international students had a slightly higher mean for overall acculturative stress levels.

Table 3. Means and standard deviations for values for sociocultural adaptation and five subscales of sociocultural adaptation by age (traditional and non-traditional students).

\begin{tabular}{lcccc}
\hline & \multicolumn{2}{c}{ Traditional } & \multicolumn{2}{c}{ Non-traditional } \\
\cline { 2 - 5 } & $\boldsymbol{N}$ & $\boldsymbol{M}(\boldsymbol{S D})$ & $\boldsymbol{N}$ & $\boldsymbol{M}(\boldsymbol{S D})$ \\
\hline $\begin{array}{l}\text { Sociocultural adaptation } \\
\text { Sociocultural adaptation subscales }\end{array}$ & 266 & $3.46(0.60)$ & 133 & $3.55(0.64)$ \\
$\quad$ Interpersonal communication & 266 & $3.39(0.67)$ & 133 & $3.49(0.73)$ \\
$\quad$ Academic/work performance & 266 & $3.55(0.69)$ & 133 & $3.72(0.74)$ \\
$\quad \begin{array}{l}\text { Personal interests and community } \\
\quad \text { involvement }\end{array}$ & 266 & $3.33(0.68)$ & 133 & $3.33(0.75)$ \\
$\quad$ Ecological adaptation & 266 & $3.47(0.73)$ & 133 & $3.59(0.74)$ \\
$\quad$ Language proficiency & 266 & $3.73(0.91)$ & 133 & $3.80(0.90)$ \\
\hline
\end{tabular}

Note. Rating of each behavior ranged from 1 (not at all competent) to 5 (extremely competent).

Table 4. Means and standard deviations for sociocultural adaptation and five subscales of sociocultural adaptation by degree level.

\begin{tabular}{lrcrc}
\hline & \multicolumn{2}{c}{ Undergraduate } & \multicolumn{2}{c}{ Graduate } \\
\cline { 2 - 5 } & $\boldsymbol{N}$ & $\boldsymbol{M}(\boldsymbol{S D})$ & $\boldsymbol{N}$ & $\boldsymbol{M}(\boldsymbol{S D})$ \\
\hline Sociocultural adaptation & 255 & $3.48(0.58)$ & 156 & $3.52(0.66)$ \\
Sociocultural adaptation subscales & & & & \\
$\quad$ Interpersonal communication & 255 & $3.41(0.67)$ & 156 & $3.48(0.71)$ \\
$\quad$ Academic/work performance & 255 & $3.58(0.68)$ & 156 & $3.76(0.75)$ \\
$\quad$ Personal interests and community & 255 & $3.36(0.69)$ & 156 & $3.29(0.74)$ \\
$\quad$ involvement & & & & \\
$\quad$ Ecological adaptation & 255 & $3.50(0.70)$ & 156 & $3.55(0.78)$ \\
$\quad$ Language proficiency & 255 & $3.76(0.84)$ & 156 & $3.93(1.00)$ \\
\hline
\end{tabular}

Note. Rating of each behavior ranged from 1 (not at all competent) to 5 (extremely competent). 
An ANOVA was conducted to test the differences between degree level and overall sociocultural adaptation levels based on the five subscales of sociocultural adaptation among the international students. Significant differences were not evident between the mean values; however, graduate international students had a slightly higher mean for overall sociocultural adaptation levels, along with the four subscales of interpersonal communication, academic and work performance, ecological adaptation, and language proficiency. Undergraduate international students had a slightly higher mean for the sociocultural adaptation subscale of personal interests and community involvement.

The demographic variable of English language comfort was alss examined. Particular to this factor, students selected their level of comfor with the English language, which included the options of not comfortable somewhat comfortable, comfortable, very comfortable, and extremel. comfortable. The categories of English language comfort were compiled ints three groups that included students who were somewhat comfortableincluding not comfortable and somewhat comfortable-(22\%); comfortabli $(39 \%)$; and extremely comfortable-including very comfortable anc extremely comfortable (39\%).

An ANOVA was conducted to test the differences between Englisl language comfort and acculturative stress among the international students it the study. A significant difference was found for the variable of acculturativi stress $(F=15.86,2,405, p<.0001)$. Tukey's post hoc analysis indicates tha a significant difference occurred between students who were somewha comfortable and extremely comfortable, as well as comfortable anc extremely comfortable with English, which indicates a large difference witl students who were extremely comfortable with the English language anc those who were not.

An ANOVA was also conducted to test the differences betwee1 English language comfort and overall sociocultural adaptation levels, alon with the five subscales of sociocultural adaptation among the internationa students. Significant differences were evident for overall sociocultura adaptation levels $(F=27.51,2,409, p<.0001)$, along with the five subscale: of sociocultural adaptation that included interpersonal communication $(F=$ $32.18,2,409, p<.0001)$; academic/work performance $(F=26.59,2,409,1$ $<.0001)$; personal interests and community involvement $(F=8.24,2,409$, 1 $<.0003)$; ecological adaptation $(F=7.68,2,409, p<.0005)$; and languag proficiency $(F=23.52,2,409, p<.0001)$. Tukey's post hoc analyse revealed a significant difference between students who were somewha comfortable and extremely comfortable, as well as comfortable anc 
extremely comfortable for the variables of overall sociocultural adaptation and the four subscales of sociocultural adaptation (academic/work performance, personal interests and community involvement, ecological adaptation, and language proficiency). These results indicate a large difference with students who were extremely comfortable with the English language and those who were not. The subscale of interpersonal communication showed a significant difference between all three categories of English language comfort as Tukey's post hoc analysis indicated differences between the categories of somewhat comfortable and comfortable, somewhat comfortable and extremely comfortable, and comfortable and extremely comfortable.

Table 5. Means and standard deviations for sociocultural adaptation and five subscales of sociocultural adaptation by English comfort level.

\begin{tabular}{|c|c|c|c|c|c|c|}
\hline & \multicolumn{2}{|c|}{$\begin{array}{c}\text { Somewhat } \\
\text { comfortable }\end{array}$} & \multicolumn{2}{|c|}{ Comfortable } & \multicolumn{2}{|c|}{$\begin{array}{c}\text { Extremely } \\
\text { comfortable }\end{array}$} \\
\hline & $N$ & $M(S D)$ & $N$ & $M(S D)$ & $N$ & $M(S D)$ \\
\hline $\begin{array}{l}\text { Sociocultural } \\
\text { adaptation }\end{array}$ & 92 & $3.24(0.48)$ & 161 & $3.39(0.56)$ & 159 & $375(0.63)$ \\
\hline \multicolumn{7}{|l|}{$\begin{array}{l}\text { Sociocultural } \\
\text { adaptation subscales }\end{array}$} \\
\hline $\begin{array}{l}\text { Interpersonal } \\
\text { communication }\end{array}$ & 92 & $3.09(0.56)$ & 161 & $3.34(0.60)$ & 159 & $3.73(0.71)$ \\
\hline $\begin{array}{l}\text { Academic/work } \\
\text { performance }\end{array}$ & 92 & $3.33(0.59)$ & 161 & $3.48(0.67)$ & 159 & $3.91(0.70)$ \\
\hline $\begin{array}{l}\text { Personal interests } \\
\text { and community } \\
\text { involvement }\end{array}$ & 92 & $3.21(0.67)$ & 161 & $3.24(0.68)$ & 159 & $3.51(0.71)$ \\
\hline $\begin{array}{l}\text { Ecological } \\
\text { adaptation }\end{array}$ & 92 & $3.36(0.62)$ & 161 & $3.44(0.72)$ & 159 & $3.69(0.76)$ \\
\hline $\begin{array}{l}\text { Language } \\
\text { proficiency }\end{array}$ & 92 & $3.41(0.77)$ & 161 & $3.62(0.83)$ & 159 & $4.12(0.92)$ \\
\hline
\end{tabular}

Note. Rating of each behavior ranged from 1 (not at all competent) to 5 (extremely competent).

\section{DISCUSSION AND CONCLUSIONS}

In investigating the level of acculturative stress related to the levels of overall sociocultural adaptation and the five subscales of sociocultural 
adaptation, the correlations between acculturative stress and sociocultural adaptation indicated a significant negative relationship among the variables. This finding denoted that as acculturative stress increased, levels of students' sociocultural adaptation decreased and as acculturative stress scores decreased, students' levels of sociocultural adaptation increased. The five subscales also indicate a significant negative relationship with acculturative stress. The results also demonstrated that students with greater competency in interpersonal communication, academic/work performance, personal interests and community involvement, ecological adaptation, and language proficiency usually experience lower levels of acculturative stress.

The results of students' demographic factors indicated significant differences with gender, age, degree level, and English language. In particular, male students reported higher levels of acculturative stress and females reported higher levels of sociocultural adaptation. In addition, students of nontraditional age and graduate students had slightly higher levels of satisfaction with their overall college experience than traditional and undergraduate international students. Significant differences were also evident with English language comfort across all dependent variables, particularly between students who reported the highest levels of English language comfort and those who reported lower levels of English language comfort.

A significant relationship between the levels of acculturative stress and overall sociocultural adaptation existed in this study. The results showed that acculturative stress levels negatively correlate with levels of sociocultural adaptation among international students living in a new cultural environment. This finding implied that, as acculturative stress levels increase for international students, their levels of sociocultural adaptation decrease and as levels of acculturative stress decrease, students' sociocultural adaptation to the university environment increases. In addition, all five subscales of sociocultural adaptation resulted in a significant negative relationship with acculturative stress. This summation might suggest that greater competency with interpersonal communication, academic/work performance, personal interests and community involvement, ecological adaptation, and language proficiency can each reduce levels of acculturative stress among international students. As suggested by Wang and Mallinckrodt (2006), the factor of acculturative stress is important in analyzing sociocultural adjustment difficulties.

In terms of the demographic variable of gender, a significan difference was evident between the female and male international students Results indicated that the female international students had slightly highe 
levels of competency in sociocultural adaptation to a new cultural environment compared to the male students. Male international students had a significant higher mean score for acculturative stress, which coincided with their slightly lower mean scores for sociocultural adaptation. This indicated that the male international students perceive facing slightly greater challenges and difficulties adjusting to the campus environment. In contrast, Wilson's (2011) study found that female international graduate students at a private urban, mid-sized Northeastern university had more difficulty adapting to the environment than male students This finding is similar with other studies that indicated female international students encountered higher levels of stress, anxiety, and homesickness (Doa, Lee, \& Chang, 2007; Fatima, 2001; Hsieh, 2006; Kwon, 2009), and more problems socially and academically when compared to male students (Mallinckrodt \& Leong, 1992). However, difficulties experienced by males were not significantly different than females, representing that further research should be considered regarding gender differences (Wilson, 2011).

A significant difference resulted for the sociocultural adaptation subscale of academic/work performance and non-traditional students, as non-traditional students had higher mean values. Non-traditional students also had higher mean values for the remaining four subscales of sociocultural adaptation, which included interpersonal communication, personal interests and community involvement, ecological adaptation, and language proficiency. Nontraditional students also had a higher mean for overall satisfaction with the college experience. In addition, these results correspond to the higher mean value for acculturative stress among the undergraduate international students, as they had lower levels of sociocultural adaptation.

Regarding the demographic factor of degree level, the only variable resulting in a significant difference between undergraduate and graduate students was students' overall satisfaction with the college experience. Graduate students had higher mean scores for overall sociocultural adaptation levels and the four subscales of sociocultural adaptation that included interpersonal communication, academic/work performance, ecological adaptation, language proficiency, and satisfaction with the university. In contrast, the undergraduate international students had higher mean values for acculturative stress, indicating that these students face greater challenges and difficulties during their stay at the university. The findings relative to students' degree level coincide with the demographic variable of age, as undergraduate students most often are of traditional age and graduate students are commonly of nontraditional age. 
A significant difference was found between international students English language comfort and all dependent variables as the demographir factor of English language comfort showed significant differences for al dependent variables. In terms of English language fluency, students witl increased language barriers experience greater difficulties adapting to thr host culture (Doa et al., 2007). Therefore, lower language proficiency relate: to decreased levels of intercultural competence (Hismanoglu, 2011). A Khatiwada (2010) reported, English language proficiency is a significan predictor of sociocultural adaptation, as the development of language skill helps international students to gain a better understanding of local culture anc sociocultural aspects of daily life.

All students who begin college must adjust to the new environment in some shape or form. However, in comparison to domestic U.S. college students, international students face greater difficulties in adapting to the university, particularly as they experience more distress during their initial transition to a new country and cultural environment (HechanovaAlampapy, Beehr, Christiansen, \& VanHorn, 2002; Poyrazli \& Grahame, 2007; Wilton \& Constantine, 2003). Gaining an understanding of the acculturation experiences among international students can serve as guidance for higher education administrators, faculty, and staff to adequately meet the needs of International students. This study is significant because it adds to the body of knowledge as the data gathered in this study provide a better understanding of the levels of acculturative stress and sociocultural adaptation among international students. This study also provides evidence that significant relationships exist between international students' levels of acculturative stress and sociocultural adaptation and that significant differences are evident among certain demographic factors, especially gender and English language comfort.

\section{Limitations}

The primary limitation of this study was the narrow range of students surveyed as all participants were international students from one institution located in the south central region of the United States; therefore, it is difficult to generalize the results. Other higher education institutions, particularly those located in varying geographical areas, may have different

international student representation, campus culture, and university initiatives. International student experiences at the targeted institution may vary in comparison to other institutions. For this reason, applicability to other colleges and universities and geographical areas is limited. In addition, 
as English was a second language to the majority of international students, a language barrier with English language fluency could have varied the interpretation of survey items and influenced the results. Also, for this study, international students' country of origin was quite diverse in representation and in numbers, creating difficulties in making inferences about the population based on nationality.

\section{IMPLICATIONS}

This research study has implications for higher education policy and practice because it adds to a growing body of research on the acculturation process of international student in the United States. As higher education institutions recognize the importance in providing international student services on their campuses (Mamiseishvili, 2012), these research findings reinforced how imperative it is for these institutions to aid international students in their transition to college as trends indicate that the number of globally mobile students is expected to triple to eight million by 2025 (Altbach \& Basset, 2004). Increasing knowledge about the effects of acculturative stress and sociocultural adaptation of international students can assist higher education professionals with providing appropriate support services to assist international students with their transition to higher education in the United States. As Sumer (2009) stated, "In order for U.S. colleges and universities to better accommodate the significant number of international students and to recruit them in the future, it is critical to identify factors that influence these students' adjustment" (p. 3).

\section{REFERENCES}

Adnett, N. (2010). The growth of international students and economic development: Friends or foes? Journal of Education Policy, 25, 625-637. doi: 10.1080/02680931003782827

Al-Sharideh, K. A., \& Goe, W. R. (1998). Ethnic communities within the university: An examination of factors influencing the personal adjustment of international students. Research in Higher Education, 39, 699-725. doi: 10.1023/A:1018714125581

Allameh, J. (1989). Just who are these international students anyway? Retrieved from ERIC database. (ED319260)

Altbach, P. G., \& Basset, R. M. (2004). The brain trade. Foreign Policy, 144, 30 32. doi: $10.2307 / 4152974$ 
Andrade, M. S. (2006). International students in English-speaking universities: Adjustment factors. Journal of Research in International Education, 5, 131-154. doi: $10.1177 / 1475240906065589$

Aponte, J. F., \& Johnson, L. R. (2000). The impact of culture on the intervention and treatment of ethnic populations. In J. F. Aponte \& J. Wohl (Eds.), Psychological interventions and cultural diversity (2nd ed., pp. 18-39). Boston, MA: Allyn \& Bacon.

Babbie, E. R. (2010). The practice of social research (12th ed.). Belmont, CA: Wadsworth Cengage.

Berry, J. W. (2005). Acculturation: Living successfully in two cultures. International Journal of Intercultural Relations, 29, 697-712. doi: 10.1016/j.ijintrel.2005.07.013

Berry, J. W., Kim, U., Minde, T., \& Mok, D. (1987). Comparative studies of acculturative stress. International Migration Review, 21, 491-511. doi: $10.2307 / 2546607$

Berry, J. W., \& Sam, D. L. (1997). Acculturation and adaptation. In J. W. Berry, M. H. Segall, \& C. Kagitcibasi (Eds.), Handbook of cross-cultural psychology: Social behavior and applications (pp. 291-326). Needham Heights, MA: Allyn \& Bacon.

Burbules, N. C., \& Torres, C. A. (Eds.). (2000). Globalization and education: Critical perspectives. New York: Routledge.

Butcher, A., \& McGrath, T. (2004). International Students in New Zealand: Needs and responses. International Education Journal, 5, 540-551.

Chow, P. (2011). What international students think about U.S. higher education: Attitudes and perceptions of prospective students in Africa, Asia, Europe, and Latin America. Institute of International Education. Retrieved from http://www.iie.org/en/Who-We-Are/News-and-Events/Press-Center/PressReleases/2011/2011-06-17-What-International-Students-Think-AboutUSHigher-Education

Constantine, M. G., Okazaki, S., \& Utsey, S. O. (2004). Self-concealment, social self-efficacy, acculturative stress, and depression in African, Asian, and Latin American international college students. American Journal of Orthopsychiatry, 74, 230-241.

Council for the Advancement of Standards in Higher Education. (2012). CAS professional standards for higher education (8th ed.). Washington, DC: Author.

Dillard, J. M., \& Chisolm, G. B. (1983) Counseling the international student in a multicultural context. Journal of College Student Personnel, 24(2), 101105.

Doa, T. K., Lee, D. H., \& Chang, H. L. (2007). Acculturation level, perceived English fluency, perceived social support level, and depression among Taiwanese international students. College Student Journal, 41(2), 287295. 
Eustace, R. W. (2007). Factors influencing acculturative stress among international students in the United States (Doctoral dissertation). Available from ProQuest Dissertations and Theses database. (UMI No. 3291368)

Fatima, N. (2001). International female graduate students' perceptions of their adjustment experiences and coping strategies at an urban research university. Paper presented at the Annual Meeting of the American Educational Research Association, Seattle, WA.

Flaskerud, J. H. (2007). Cultural competence column: Acculturation. Issues in Mental Health Nursing, 28, 543-546. doi: 10.1080/01612840701346048

Furnham, A. (2004). Education and culture shock. Psychologist, 17(1), 16.

Gall, M. D., Gall, J. P., \& Borg, W. R. (2007). Educational research: An introduction. Boston, MA: Pearson.

Gaw, K. F. (2000). Reverse culture shock in students returning from overseas. International Journal of Intercultural Relations, 24, 83-104. doi: 10.1016/ S0147-1767(99)00024-3

Hayes, R. L., \& Lin, H. R. (1994). Coming to America: Developing social support systems for international students. Journal of Multicultural Counseling \& Development, 22, 7-16. doi: 10.1002/j.2161-1912.1994.tb00238.x

Hayward, F. M. (2000). Internationalization of U.S. higher education: Preliminary status report 2000. Washington, DC: American Council on Education.

Healey, N. (2008). Is higher education 'internationalizing'? Higher Education, 55, 333-355. doi: 10.1007/s10734-007-9058-4

Hechanova-Alampay, R., Beehr, T. A., Christiansen, N. D., \& VanHorn, R. K. (2002). Adjustment and strain among domestic and international student sojourners: A longitudinal study. School Psychology International, 23, 458-475. doi: 10.1177/0143034302234007

Hismanoglu, M. (2011). An investigation of ELT students' intercultural communicative competence in relation to linguistic proficiency, overseas experience and formal instruction. International Journal of Intercultural Relations, 35, 805-817. doi: 10.1016/j.ijintrel.2011.09.001

Hsieh, M. H. (2006). Identity negotiation among female Chinese international students in second-language higher education. College Student Journal, 40(4), 870-884.

Hsu, C. (2011). Factors influencing international students' academic and sociocultural transition in an increasingly globalized society (Doctoral dissertation). Available from ProQuest LLC. (UMI No. 3455443)

Institute of International Education. (2013). Open Doors 2013: Report on international educational exchange. New York: NY: Institute of International Education. Information and Data Tables. Retrieved from http://iie.org/Researchand-Publications/Open-Doors

Johnson, N. (2011). Internationalizing your campus to attract and retain international students. Education USA Forum, Washington, DC. Retrieved from http://www.educationusa.info/conferences/educationusa_forum 
2011/presentations/Internationalizing-Your-Campus-Attract-RetainInternational-Students.pdf

Johnson, L. R., \& Sandhu, D. S. (2007). Isolation, adjustment, and acculturation issues of international students: Interventions strategies for counselors. In H. D. Singaravelu \& M. Pope (Eds.), A handbook for counseling international students in the United States (pp. 13-36). Alexandria, VA: American Counseling Association.

Jung, E., Hecht, M., \& Wadsworth, B. C. (2007). The role of identity in international students' psychological well-being in the United States: A model of depression level, identity gaps, discrimination, and acculturation. International Journal of Intercultural Relations, 31, 605-624. doi: 10.1016/j.ijintrel.2007.04.001

Kaczmarek, P. G., Matlock, G., Merta, R., Ames, M. H., \& Ross, M. (1994). An assessment of international college students' adjustment. International Journal for the Advancement of Counseling, 17, 241-247. doi: 10.1007/ BF01407740

Khatiwada, S. (2010). Deciding to come to the U.S.: International students and sociocultural adaptation (Doctoral dissertation). Available from ProQuest Dissertations and Theses database. (UMI No. 3430479)

Kwon, Y. (2009). Factors affecting international students' transition to higher education institutions in the United States. From the perspective of Office of International Students. College Student Journal, 43(4), 1020-1036.

La Spada, M. G. (2010). Globalization and its effects on diversity: Some economic aspects. Global challenges series. Paper 76. University of Messina, Messina, Italy. Retrieved from http://www.susdiv.org/uploadfiles/ED2009076.pdf

Lee, J. J., \& Rice, C. (2007). Welcome to America? International student perceptions of discrimination. Higher Education: The International Journal of Higher Education and Educational Planning, 53(3), 381-409. doi: 10.1007/s10734-005-4508-3

Li, A., \& Gasser, M. B. (2005). Predicting Asian international students' sociocultural adjustment: A test of two mediation models. International Journal of Intercultural Relations, 29(5), 561-576. doi: 10.1016/ j.ijintrel.2005.06.003

Mallinckrodt, B., \& Leong, F. T. L. (1992). Social support in academic programs and family environments: Sex differences and role conflicts for graduate students. Journal of Counseling and Development, 70, 716-723. doi: 10.1002/j.1556-6676.1992.tb02154.x

Mamiseishvili, K. (2012). International student persistence in U.S. postsecondary institutions. Higher Education: The International Journal of Higher Education and Educational Planning, 64(1), 1-17.

Mehta, S. (2011). Achievement motivation, acculturation, and gender, as predictors of psychological well-being in Asian Indian students in the U.S. (Published doctoral dissertation). Alliant International University, San Francisco, CA. 
NAFSA: Association of International Educators. (2013). The economic benefits of international students to the U.S. economy: Academic year 2012-2013. Retrieved from http://www.nafsa.org/_File/_/eis2013/USA.pdf

Obst, D., \& Forster, J. (2004). Perceptions of European higher education in third world countries: Outcomes of a study by the academic cooperation association (ACA) country report: USA. Institute of International Education. Retrieved from http://www.iie.org/en/Research-andPublications/Publications-and-Reports/IIEBookstore/Perceptions-ofEuropean-Higher-Education

Olivas, M., \& Li, C. (2006). Understanding stressors for international students in higher education: What college counselors and personnel need to know. Journal of Instructional Psychology, 33(3), 217-222.

O'Reilly, A., Ryan, D., \& Hickey, T. (2010). The psychological well-being and sociocultural adaptation of short-term international students in Ireland. Journal of College Student Development, 51(5), 584-598. doi: 10.1353/ csd.201.0011

Peterson, D. M., Briggs, P., Dreasher, L., Horner, D. D., \& Nelson, T. (1999). Contributions of international students and programs to campus diversity. New Directions for Student Services, 1999(86), 67-77. doi: 10.1002/ ss. 8609

Popov, V., Brinkman, D., Biemans, H. J. A., Mulder, M., Kuznetsov, A., \& Noroozi, O. (2012). Multicultural student group work in higher education: An explorative case study on challenges as perceived by students. International Journal of Intercultural Relations, 36(2), 302-317. doi: 10.1016/j.ijintrel.2011.09.004

Poyrazli, S., \& Grahame, K. M. (2007). Barriers to adjustment: Needs of international students within a semi-urban campus community. Journal of Instructional Psychology, 34(1), 28-45.

Poyrazli, S., Kavanaugh, P. R., Baker, A., \& Al-Timimi, N. (2004). Social support and demographic correlates of acculturative stress in international students. Journal of College Counseling, 7, 73-82. doi: 10.1002/j.2161-1882.2004. tb00261.x

Poyrazli, S., \& Lopez, M. (2007). An exploratory study of perceived discrimination and homesickness: A comparison of international students and American students. Journal of Psychology, 141(3), 263-280. doi: 10.3200/JRLP.141. 3.263-280

Roberts, P., \& Dunworth, K. (2012). Staff and student perceptions of support services for international students in higher education: A case study. Journal of Higher Education Policy \& Management, 34(5), 517-528. doi: 10.1080/1360080X.2012.716000

Sakurai, T., McCall-Wolf, F., \& Kashima, E. S. (2010). Building intercultural links: The impact of a multicultural intervention programme on social ties of international students in Australia. International Journal of Intercultural Relations, 34(2), 176-185. doi: 10.1016/j.ijintrel.2009.11.002 
Sandhu, D. S., \& Asrabadi, B. R. (1994). Development of an acculturative stress scale for international students: Preliminary findings. Psychological Reports, 75, 435-448. doi: 10.2466/pr0.1994.75.1.435

Sandhu, D. S., \& Asrabadi, B. R. (1998). An acculturative stress scale for international students: A practical approach to stress management. In C. P. Zalaquett \& R. J. Wood (Eds.), Evaluating stress: A book of resources (Vol. 2, pp. 1-33). Lanham, MD: Scarecrow.

Schmitt, M. T., Spears, R., \& Branscombe, N. R. (2003). Constructing a minority group identity out of shared rejection: The case of international students. European Journal of Social Psychology, 33, 1-12. doi: 10.1002/ejsp.131

Sobré-Denton, M. (2011). The emergence of cosmopolitan group cultures and its implications for cultural transition: A case study of an international student support group. International Journal of Intercultural Relations, 35(1), 7991. doi: 10.1016/j.ijintrel.2010.09.007

Stromquist, N. P. (2007). Internationalization as a response to globalization: Radical shifts in university environments. Higher Education: The International Journal of Higher Education and Educational Planning, 53(1), 81-105. doi: 10.1007/s10734-005-1975-5

Sumer, S. (2009). International students' psychological and sociocultural adaptation in the Unites States (Doctoral dissertation). Available from ProQuest Dissertations and Theses database. (3401617)

Swami, V. (2009). Predictors of sociocultural adjustment among sojourning Malaysian students in Britain. International Journal of Psychology, 44(4), 266-273. doi: 10.1080/00207590801888745

Thiuri, P. (2011). International student satisfaction with student services at the rochester institute of technology (Doctoral dissertation). Available from ProQuest LLC. (UMI No. 3481441)

Thomas, K., \& Althen, G. (1989). Counseling foreign students. In P. B. Pedersen, J. G. Draguns, W. J. Lonner, \& J. E. Trimble (Eds.), Counseling across cultures (3rd ed., pp. 205-241). Honolulu, HI: University of Hawaii Press.

Wang, C. D. C., \& Mallinckrodt, B. (2006). Acculturation, attachment, psychological adjustment of Chinese/Taiwanese international students. Journal of Counseling and Psychology, 53, 422-433. doi: 10.1037/00220167.53.4.422

Ward, C., \& Kennedy, A. (1992). Locus of control, mood disturbance, and social difficulty during cross-cultural transitions. International Journal of Intercultural Relations, 16, 175-194. doi: 10.1016/0147-1767(92)90017-O

Ward, C., \& Kennedy, A. (1993a). Psychological and socio-cultural adjustment during cross-cultural transitions: A comparison of secondary students overseas and at home. International Journal of Psychology, 28(2), 129147. doi: 10.1080/00207599308247181

Ward, C., \& Kennedy, A. (1993b). Where's the culture in cross-cultural transition? Comparative studies of sojourner adjustment. Journal of Cross-Cultural Psychology, 24, 221-249. doi: 10.1177/0022022193242006 
Ward, C., \& Kennedy, A. (1996). Before and after cross-cultural transition: A study of New Zealand volunteers on field assignments. In H. Grad, A. Blanco, \& J. Georgas (Eds.), Key issues in cross-cultural psychology (pp. 138-154). Lisse, Netherlands: Swets \& Zeitlinger.

Ward, C., \& Kennedy, A. (1999). The measurement of sociocultural adaptation. Intercultural Journal of Intercultural Relations, 23, 659-677. doi: 10.1016/ S0147-1767(99)00014-0

Ward, C., \& Rana-Deuba, A. (1999). Acculturation and adaptation revisited. Journal of Cross-Cultural Psychology, 30, 422-442. doi: 10.1177/ 0022022199030004003

Ward, C., \& Searle, W. (1991). The impact of value discrepancies and cultural identity on psychological and sociocultural adjustment of sojourners. International Journal of Intercultural Relations, 15, 209-225. doi: 10.1016/ 0147-1767(91)90030-K

Wildavsky, B. (2010, August 26). University globalization is here to stay. Chronicle of Higher Education. Retrieved from http://chronicle.com/article/ University-Globalization-Is/124148/

Wilson, G. P. (2011). Fitting in: Sociocultural adaptation of international graduate students. NERA Conference Proceedings 2011. Paper 21. Retrieved from http://digitalcommons.uconn.edu/nera_2011/21

Wilson, J. (2012). Exploring the past, present and future of cultural competency research: The revision and expansion of the sociocultural adaptation construct. (Unpublished doctoral dissertation). Victoria University of Wellington, Wellington, New Zealand.

Wilton, L., \& Constantine, M. G. (2003). Length of residence, cultural adjustment difficulties, and psychological distress in Asian and Latin-American international college students. Journal of College Counseling, 6, 177-186. doi: 10.1002/j.2161-1882.2003.tb00238.x

Witherel, S., \& Pittman, S. (2012). International education exchanges are at alltime high, strengthening economies and societies around the world. Retrieved from http://www.iie.org/en/Who-We-Are/News-and-Events/ Press-Center/Press-Releases/2012/11-13-2012-Open-Doors-InternationalStudents

Yeh, G. J., Ma, P. W., Madan, A., Hunter, G. D., Jung, S., Kim, A., Akitaya, K, \& Sasaki, K. (2005). The cultural negotiations of Korean immigrant youth. Journal of Counseling and Development, 83, 172-181. doi: 10.1002/ j.1556-6678.2005.tb00594.x

HAJARA MAHMOOD, EdD, is an Associate Director for the Center of Teaching and Learning Excellence and Biology Instructor at Embry-Riddle Aeronautical University. Her research area focuses on meeting the learning needs for diverse student populations, effective pedagogical practices, STEM education, retention initiatives, and issues and trends in higher education. Email: hajara.mahmood@erau.edu 
MONICA GALLOWAY BURKE, PhD, is an Associate Professor in the area of student affairs in higher education at Western Kentucky University. Her research and teaching focus on topics related to student affairs, diversity, counseling and helping concepts, self-care, student development, and professional development and practice in student affairs. Email: monica.burke@wku.edu 